\title{
Production, Characterization and Surface Properties of Sr Doped Hydroxyapatite Coating on Magnesium Alloy by Hydrothermal Method
}

\author{
Turan Gurgenc ${ }^{*}$ (]) \\ Firat University, Automotive Engineering, 23119, Elazig, Turkey
}

\begin{abstract}
In this study, the surface of AZ91D magnesium alloy was coated with undoped and at different ratios strontium doped hydroxyapatite. Coatings were carried out at $180{ }^{\circ} \mathrm{C}$ in 3 hours. The surface roughness of the coated samples was determined and the microstructure of the phases forming on the coated surfaces were examined by scanning electron microscopy (SEM). The chemical composition of the phases formed on the coated surfaces was determined by energy dispersed X-ray spectroscopy (EDS). The phases formed on the surfaces were characterized by X-Ray diffraction (XRD) and Fourier transform infrared spectrometry (FT-IR). The AZ91D magnesium alloy was coated successfully with undoped and strontium doped hydroxyapatite by hydrothermal method. The highest surface roughness value was measured as $R_{a}=8.255 \mu \mathrm{m}$ in $15 \%$ strontium doped sample. It was determined that the $(\mathrm{Ca}+\mathrm{Sr}) / \mathrm{P}$ ratios of the coatings were higher than the stoichiometric ratio of hydroxyapatite, 1.67. It was determined that the closest coating to the stoichiometric ratio was $10 \% \mathrm{Sr}$ doped coating.
\end{abstract}

Keywords: Hydroxyapatite coating, Magnesium alloy, Hydrothermal method, Surface roughness, Biomaterial.

\section{INTRODUCTION}

Repairing damaged bone tissue one of the important topics in tissue engineering. Implant materials used in tissue engineering should be biocompatible and biodegradable in the human body during the repair of bone tissues [1]. In recent years, magnesium $(\mathrm{Mg})$ alloys have become very interesting among metallic implants due to their important advantages especially in orthopedic applications. These advantages include its extremely lightweight, limited biological reactions, biodegradability, outstanding mechanical properties close to natural bone, and excellent biocompatibility. In addition, the presence of $\mathrm{Mg}^{2+}$ ions in apatite crystals can increase osteoblast adhesion rate and increase bone formation [2-4]. Besides these advantages, low wear-resistance and weak corrosion resistance especially in physiological solution are the most important disadvantages of $\mathrm{Mg}$ implants. In the implants exposed to corrosion and wear, the mechanical properties deteriorate before sufficient bone healing and limits their usage by preventing the use of implants as a load-bearing material $[2,3]$. The most effective and efficient way to avoid these disadvantages of $\mathrm{Mg}$ implants is to increase their corrosion resistance, wear-resistance and biocom- patibility by modification their surfaces with a biocompatible protective coating $[2,5]$. Synthetic hydroxyapatite is one of the most preferred among biocompatible coatings $\left(\mathrm{Ca}_{10}\left(\mathrm{PO}_{4}\right)_{6}(\mathrm{OH})_{2}, \mathrm{HA}\right)$. This is because hydroxyapatite has the most similarity to the mineral part of the bone, excellent biocompatibility, good biodegradability and high osteogenic potential $[6,7]$.

The most commonly used techniques for coating the surfaces of Mg alloys with HA are sol-gel, electrodeposition, biomimetic method, atmospheric plasma spraying and hydrothermal method. Among these methods, hydrothermal method has advantages such as being simple, cost effective and needing low temperatures [8].

Strontium ( $\mathrm{Sr}$ ) is an element in the human body that is usually found in the body skeleton and has bone targeting properties. Sr has some positive properties like playing an important role in bone formation, the presence of $\mathrm{Sr}$ ions in biological environments, greatly increasing osteoblast differentiation, antimicrobial effect, inhibiting osteoclast activity, increasing preosteoblastic cell proliferation and bone matrix synthesis. Due to such positive properties, $\mathrm{Sr}$ has been doped to HA in recent years for improving the biological
* Corresponding authour

Email: tgurgenc@firat.edu.tr 
performance of HAs $[9,10]$.

Zhang et al. coated the surface of AZ31 magnesium alloy with hydroxyapatite by hydrothermal method at different temperatures and times [11]. Sun et al. investigated the coating surface properties and corrosion resistance of the AZ91D magnesium alloy, which they coated with fluorinated hydroxyapatite by hydrothermal method [8]. Yang et al. coated the surface of the ZK60 magnesium alloy with hydroxyapatite by hydrothermal method at different times [12]. In another study, Mg-2.9Gd-1.5Nd-0.3Zn-0.3Zr magnesium alloy was coated with hydroxyapatite by hydrothermal method [13]. Li et al. coated the surface of pure magnesium with calcium phosphate by hydrothermal method [14]. Asl et al. coated the surface of the AZ31 magnesium alloy with calcium phosphate by hydrothermal method at different temperatures [15]. Wang et al. coated the ZK60 magnesium alloy with Sr doped hydroxyapatite at different doping ratios (3\%, $5 \%$ and $10 \%)$ by hydrothermal method [16].

As a result of the literature studies, not many studies have been encountered regarding the coating of AZ91D magnesium alloy with Sr doped hydroxyapatite by hydrothermal method and it has been decided to carry out this study. In this study, the surface of AZ91D magnesium alloy was coated with $\mathrm{Sr}$ doped hydroxyapatite in different doping ratios by hydrothermal method in constant process parameters. Surface roughness of coated surfaces was determined and microstructural properties of coated surfaces were analyzed by FT-IR, SEM, EDS and XRD.

\section{EXPERIMENTAL DETAILS}

In present study, AZ91D magnesium alloy with a diameter of $20 \mathrm{~mm}$ and a thickness of $10 \mathrm{~mm}$, whose chemical composition is given in Table 1, was used as the substrate material. The substrate material was polished with 1200 mesh $\mathrm{SiC}$ sandpaper and then cleaned with ultrasonic bath for 15 min. with acetone and then dried with hot air. For HA coating, firstly $0.1 \mathrm{M}$ Merck brand $\mathrm{Ca}\left(\mathrm{NO}_{3}\right)_{2} \cdot 4 \mathrm{H}_{2} \mathrm{O}$ was added to $30 \mathrm{ml}$ of pure water in the beaker and stirred for $30 \mathrm{~min}$. at room temperature in a magnetic stirrer. Fluka analytical brand $0.06 \mathrm{M} \mathrm{H}_{9} \mathrm{~N}_{2} \mathrm{O}_{4} \mathrm{P}$ was added to $30 \mathrm{ml}$ of pure water in a second beaker and stirred for $30 \mathrm{~min}$. at room temperature in a magnetic stirrer. The mixture containing $\mathrm{H}_{9} \mathrm{~N}_{2} \mathrm{O}_{4} \mathrm{P}$ was then poured into the mixture containing $\mathrm{Ca}\left(\mathrm{NO}_{3}\right)_{2} \cdot 4 \mathrm{H}_{2} \mathrm{O}$ and stirred together for 30 minutes at room temperature in a magnetic stirrer. The $\mathrm{pH}$ of the mixture was adjusted to 4 with $\mathrm{HNO}_{3}$ while stirring was continiue. Finally, after stirring this mixture for another $10 \mathrm{~min}$. in a magnetic stirrer, it was ultrasonicated for $30 \mathrm{~min}$. and the final mixture was obtained. After the substrate material was placed on the bottom of the autoclave, the final solution was poured into the autoclave and placed in the hydrothermal reactor. Hydrothermal treatment was carried out at $180^{\circ} \mathrm{C}$ for 3 hours and when the reactor temperature reached room temperature, the sample was removed and washed several times with pure water and then dried at $60{ }^{\circ} \mathrm{C}$ for 1 hour. Production methods of $\mathrm{Sr}$ doped samples are the same as HA coating. Only for the production of $\mathrm{Sr}$ additive samples, Acros organic brand $\mathrm{Sr}\left(\mathrm{NO}_{3}\right)_{2}$ was added in different $[\mathrm{Sr}] /[\mathrm{Sr}+\mathrm{Ca}]$ molar ratios (5\%,10\%,15\% and 20\%,) keeping the molarity constant for the first solution containing $\mathrm{Ca}\left(\mathrm{NO}_{3}\right)_{2} \cdot 4 \mathrm{H}_{2} \mathrm{O}$. Pure hydroxyapatite coated sample was named HA and 5\%, $10 \%, 15 \%$ and $20 \%$ Sr doped samples were named as Sr5HA, Sr10HA, Sr15HA and Sr20HA, respectively.

The surface roughness of the produced samples was determined using the Mitutoyo SJ-201 profilometer. Measurements were carried out from 10 different points of the coating surfaces and the surface roughness values were calculated by calculating the average. Microstructures of sample surfaces were examined with ZEISS EVO-MA10 brand SEM device in different magnifications. The chemical compositions of the coated surfaces were measured using the Bruker brand EDS detector connected to the ZEISS EVOMA10 brand SEM device. The phases formed on coated surfaces were determined by XRD. XRD analyzes were performed on the Malvern Panalytical brand device at $\mathrm{CuK} \alpha(\lambda$ $=1.5406 \AA$ ) radiation, $2 \theta=20-90^{\circ}$ scanning range at $40 \mathrm{~mA}$ and $45 \mathrm{kV}$. FT-IR analysis was carried out on Thermo Scientific Nicolet IS 5 brand FT-IR spectrometer device with a scanning range of $4000-550 \mathrm{~cm}^{-1}$.

\section{RESULTS AND DISCUSSION}

Figure 1 shows the coating surface images of samples coated with hydrothermal method. As can be seen, AZ91D magnesium alloy was successfully coated with undoped and $\mathrm{Sr}$ doped hydroxyapatite by hydrothermal method. No visible cracks or porosity were found on the coating surfaces. In addition, the coating layer is combined with the substrate surface well.

Table 1. Chemical composition of AZ91D (at.-\%).

\begin{tabular}{|c|c|c|c|c|c|c|}
\hline $\mathrm{Mg}$ & $\mathrm{Al}$ & $\mathrm{Zn}$ & $\mathrm{Mn}$ & $\mathrm{Cu}$ & $\mathrm{Si}$ & Other meta \\
\hline $88-90.50$ & $8.5-9.5$ & $0.45-0.9$ & $0.17-0.4$ & 0.025 max. & 0.050 max. & Rest \\
\hline
\end{tabular}

Figure 1. Macro surface images of coated samples. 
The surface roughness values of the coated samples are seen in Figure 2. Surface roughness value of the sample coated with HA is lower than the Sr doped samples. Surface roughness increased with increasing Sr doping ratio up to $15 \%$. Then, when the Sr doping ratio reaches to $20 \%$, the surface roughness value decreased. This change in surface roughness is thought to occur due to the change in the shape and size of the crystals formed on the coated surface due to different doping ratios $[15,17]$. In implants generally rough surfaces are preferred compared to a smooth surface. This is because of the surface roughness is an important factor for better osseointegration and biomechanical bonding. Thanks to the surface roughness, a better adhesion can be achieved between the implant surface and the bone [17]. The SEM photos are shown in Figure 3 also confirm the different microstructures formed on the coating surfaces. Similar shaped structures have also been seen in previous researches on hydroxyapatite coating of magnesium alloys by hydrothermal method $[12,15]$. The coating surfaces of HA coated samples consisted of fine-grained triclinic and hexagonal structures compared to Sr-doped samples (Figure 3a and b). In $\mathrm{Sr}$ doped samples, these structures are more coarse and there are some spherical shaped particles in between these structures (Figure 3c-i). EDS analysis results obtained from coating surfaces at low magnification are given in Table 2. The $(\mathrm{Ca}+\mathrm{Sr}) / \mathrm{P}$ ratio of all samples is higher than 1.67 , which is the stoichiometric ratio of $\mathrm{HA}$, and the sample with the closest value to this ratio is $10 \% \mathrm{Sr}$ doped sample [18]. As expected, as the $\mathrm{Sr}$ doping rate increased, the Sr composition in the coating layer increased. The $(\mathrm{Ca}+\mathrm{Sr}) / \mathrm{P}$ ratio of the flower-shaped structure at point- 1 in Figure $3 \mathrm{~b}$ is 1.88 and the crystal at point- 2 is 2.01 . In the Sr5HA sample, the crystalline (Figure 3d-point-3) $(\mathrm{Ca}+\mathrm{Sr}) / \mathrm{P}$ ratio is 1.46 and the spherical particle's $(\mathrm{Ca}+\mathrm{Sr}) / \mathrm{P}$ ratio is 1.98 (Figure $3 \mathrm{~d}$-point-4). The crystalline $(\mathrm{Ca}+\mathrm{Sr}) / \mathrm{P}$ ratio at point -5 in Figure $3 \mathrm{f}$ is 1.80 and the particle at point 6 is 1.85 . The crystalline (Figure 3h-point-7) and particle's (Figure 3h-point 8) $(\mathrm{Ca}+\mathrm{Sr}) / \mathrm{P}$ ratios of $15 \% \mathrm{Sr}$ doped sample are 1.56 and 1.60, respectively. The crystalline $(\mathrm{Ca}+\mathrm{Sr}) / \mathrm{P}$ ratio at point -9 in Figure $3 \mathrm{i}$ is 1.52 and the particle at point 10 is 1.93 . As can be seen from the EDS analysis results, with the change of the $\mathrm{Sr}$ doping ratio, the $(\mathrm{Ca}+\mathrm{Sr}) / \mathrm{P}$ values of the structures in the coating layers changed. It has been seen also in the previous studies that the rates of doping elements change the $(\mathrm{Ca}+$ $\mathrm{M}) / \mathrm{P}(\mathrm{M}=$ doping element $)$ ratios differ $[19,20]$. In addition, the spherical shaped particles in the Sr doped samples are richer by $\mathrm{Sr}$ element and the $(\mathrm{Ca}+\mathrm{Sr}) / \mathrm{P}$ ratio of these particles are higher than the crystal structures.

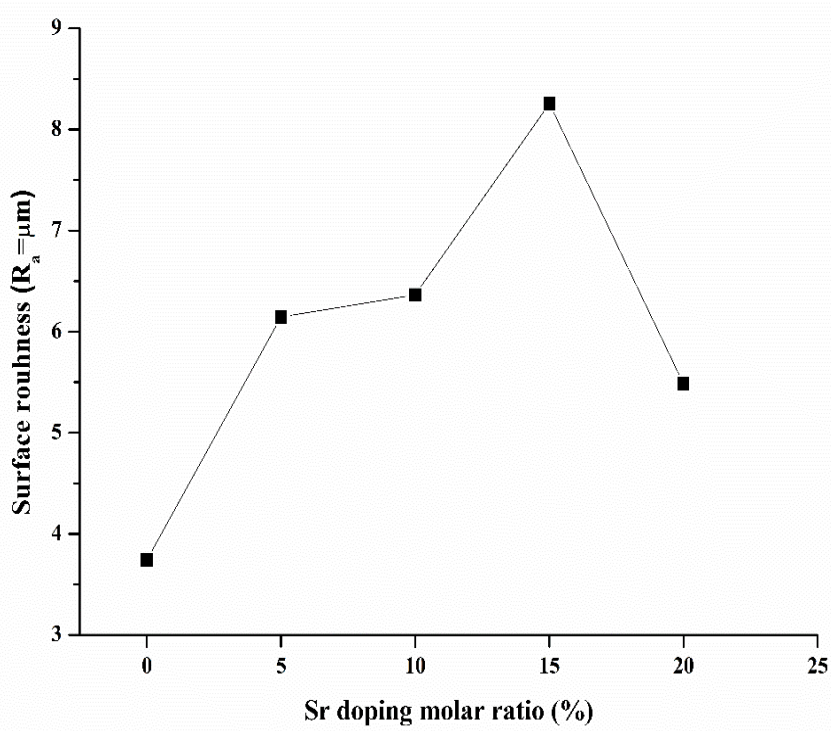

Figure 2. Surface roughness values of coated samples.

When XRD diffraction patterns of pure HA and Sr doped HA coated samples are examined, sharp HA peaks are observed alongside $\mathrm{Mg}$ peaks (Figure 4). The absence of sharp peaks of other structures other than these sharp peaks indicates that the coatings are highly crystalline and that HA coating is successfully performed on $\mathrm{Mg}$ by hydrothermal method $[9,17]$. The peak intensities of Sr doped samples in the (002) planes are higher than the undoped sample and other HA peaks. This shows that the crystal plane HA (002) is directed to AZ91D in the same manner as pure Mg [18]. Again, XRD results are generally in agreement with previous researches $[18,21]$.

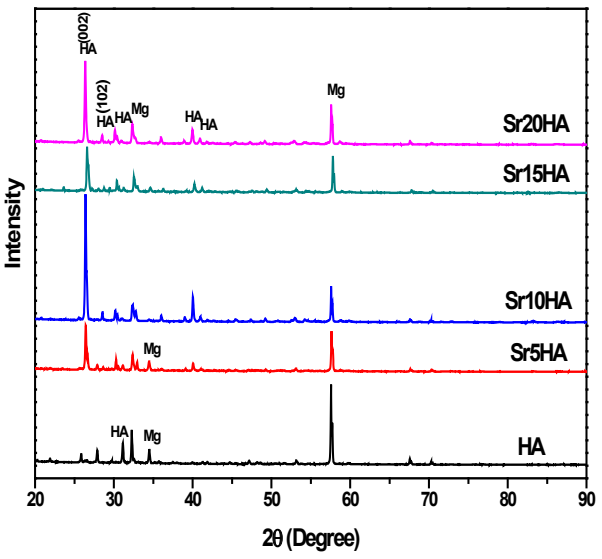

Figure 4. XRD analysis results.

FT-IR analysis results of samples are shown in Figure 5. The peak at about $601 \mathrm{~cm}^{-1}$ correspond to vibration of $\mathrm{PO}_{4}^{3-}[15$, 17]. The bands at about $1022 \mathrm{~cm}^{-1}$ and $980 \mathrm{~cm}^{-1}$ in $\mathrm{HA}$ and $1018 \mathrm{~cm}^{-1}$ in Sr5HA, $1017 \mathrm{~cm}^{-1}$ in Sr10HA, $1011 \mathrm{~cm}^{-1}$ in Sr-

Table 2. EDS analysis results taken from coating surfaces (at.-\%).

\begin{tabular}{|c|c|c|c|c|c|c|c|}
\hline Sample & $\mathrm{Ca}$ & $\mathrm{P}$ & $\mathrm{O}$ & $\mathrm{Mg}$ & $\mathrm{Zn}$ & $\mathrm{Sr}$ & $(\mathrm{Ca}+\mathrm{Sr}) / \mathrm{P}$ \\
\hline HA & 33.18 & 12.33 & 53.18 & 0.72 & 0.58 & 0.00 & 2.69 \\
\hline Sr5HA & 29.53 & 12.26 & 57.32 & 0.70 & 0.00 & 0.19 & 2.42 \\
\hline Sr10HA & 25.62 & 15.09 & 58.88 & 0.00 & 0.05 & 0.36 & 1.72 \\
\hline Sr15HA & 25.51 & 13.21 & 59.34 & 0.44 & 0.55 & 0.94 & 2.00 \\
\hline Sr20HA & 25.11 & 15.03 & 58.68 & 0.00 & 0.00 & 0.99 & 1.74 \\
\hline
\end{tabular}



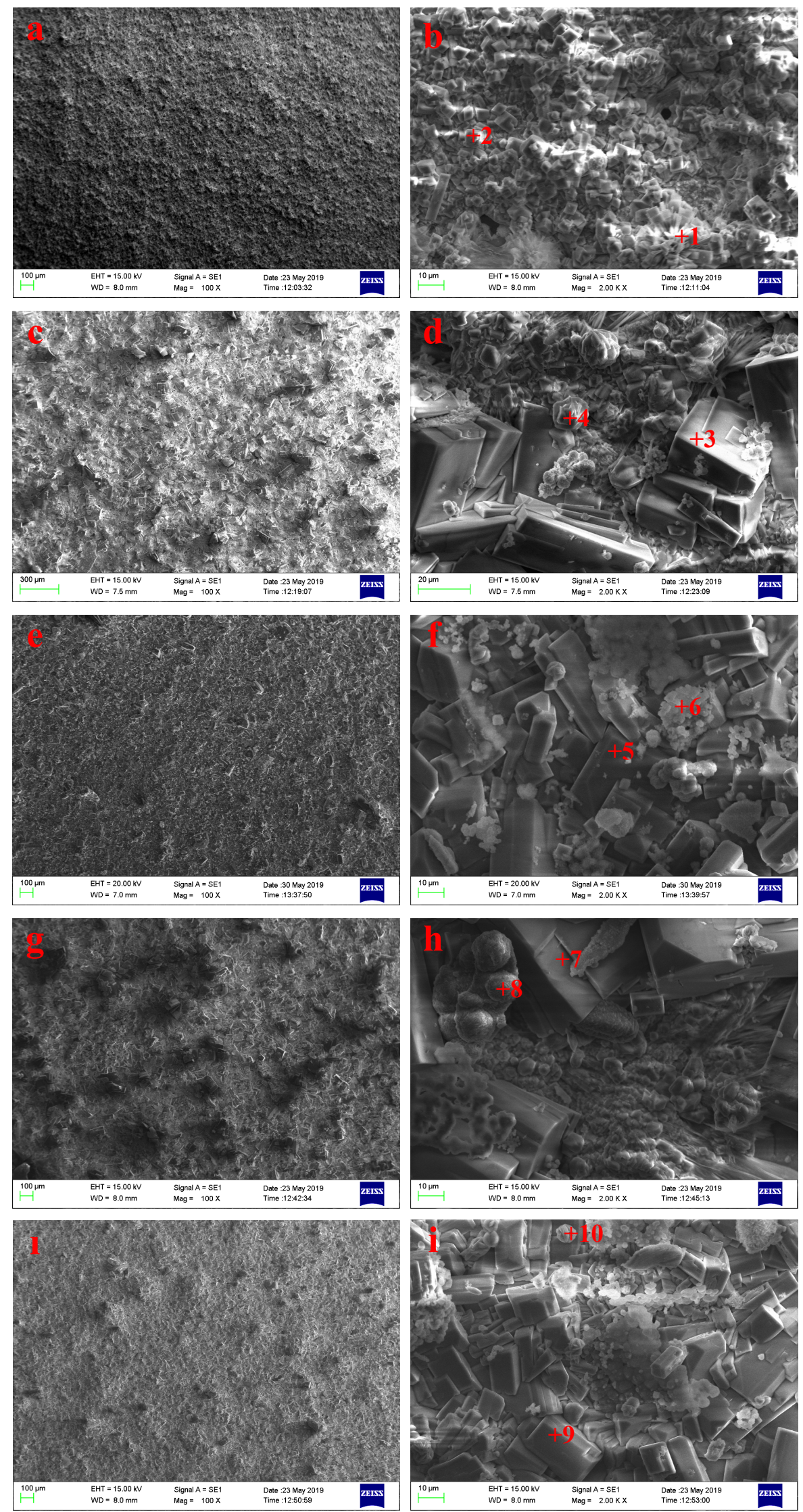

Figure 3. The coating surface SEM photographs of the samples a) HA x100, b) HA x2000, c) Sr5HA x100, d) Sr5HA x2000, e) Sr10HA x100, f) Sr10HA $\times 2000$, g) Sr15HA x100, h) Sr15HA x2000, I) Sr20HA x100 and i) Sr20HA x2000. 
$15 \mathrm{HA}$ and $1015 \mathrm{~cm}^{-1}$ in Sr20HA are ascribed to stretching modes of $\mathrm{PO}_{4}^{3-}$ [13]. The bands observed at $1651 \mathrm{~cm}^{-1}$ in Sr$10 \mathrm{HA}, 1726 \mathrm{~cm}^{-1}$ in Sr15HA and $1731 \mathrm{~cm}^{-1}$ in other samples correspond to $\mathrm{H}_{2} \mathrm{O}$ [14]. The peaks observed at about 2362 $\mathrm{cm}^{-1}$ orginate from $\mathrm{CO}_{2}$ in the air [14]. The wideband centered at approximately $3360 \mathrm{~cm}^{-1}$ is ascribed to adsorbed/ lattice water $[13,17]$.The FT-IR analysis results support to XRD analysis and are generally in agreement with the previous researches [13-15, 17].

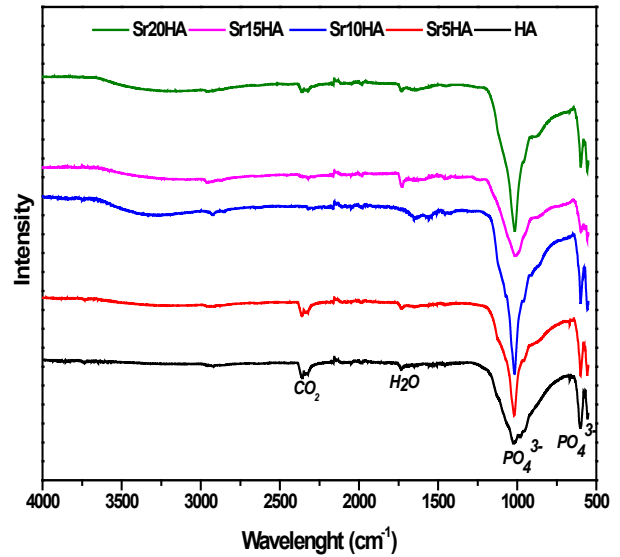

Figure 5. FT-IR analysis results.

\section{CONCLUSIONS}

- The surface of the AZ91D magnesium alloy was successfully coated with HA and Sr doped HA.

- The surface roughness value of coated surfaces increased with increasing Sr doping ratio. The coating surfaces of HA coated samples consisted of finer grained structures than $\mathrm{Sr}$ doped samples. The coating layers are generally consisted of $\mathrm{HA}$ and $\mathrm{Mg}$.

- The $(\mathrm{Ca}+\mathrm{Sr}) / \mathrm{P}$ ratios of the undoped and $\mathrm{Sr}$ doped samples are higher than the stoichiometric ratio (1.67) of HA. The closest $(\mathrm{Ca}+\mathrm{Sr}) / \mathrm{P}$ ratio to the stoichiometric ratio of $\mathrm{HA}$ was 1.72 in the sample with $10 \%$ Sr doped.

- It is thought that $10 \% \mathrm{Sr}$ doped HA coating can be used as an implant material since the surface roughness value is high and $(\mathrm{Ca}+\mathrm{Sr}) / \mathrm{P}$ ratio is closest to stoichiometric ratio.

\section{REFERENCES}

[1] Dehghanian, C., Aboudzadeh, N., Shokrgozar, M. A. (2018). Characterization of silicon-substituted nano hydroxyapatite coating on magnesium alloy for biomaterial application. Materials Chemistry and Physics, 203: 27-33. doi: 10.1016/j.matchemphys.2017.08.020

[2] Diez, M., Kang, M.-H., Kim, S.-M., Kim, H.-E., Song, J. (2016). Hydroxyapatite (HA)/poly-L-lactic acid (PLLA) dual coating on magnesium alloy under deformation for biomedical applications. Journal of Materials Science: Materials in Medicine, 27(2): 34. doi: 10.1007/ s10856-015-5643-8

[3] Bakhsheshi-Rad, H., Hamzah, E., Ismail, A., Aziz, M., Karamian, E., Iqbal, N. (2018). Bioactivity, in-vitro corrosion behavior, and antibacterial activity of silver-zeolites doped hydroxyapatite coating on magnesium alloy. Transactions of Nonferrous Metals Society of
China, 28(8): 1553-1562. doi: 10.1016/S1003-6326(18)64797-1

[4] Dunne, C. F., Levy, G. K., Hakimi, O., Aghion, E., Twomey, B., Stanton, K. T. (2016). Corrosion behaviour of biodegradable magnesium alloys with hydroxyapatite coatings. Surface and Coatings Technology, 289: 37-44. doi: 10.1016/j.surfcoat.2016.01.045

[5] Yang, H., Yan, X., Ling, M., Xiong, Z., Ou, C., Lu, W. (2015). In vitro corrosion and cytocompatibility properties of nano-whisker hydroxyapatite coating on magnesium alloy for bone tissue engineering applications. International journal of molecular sciences, 16(3): 6113-6123. doi: 10.3390/ijms16036113

[6] Shen, S., Cai, S., Bao, X., Xu, P., Li, Y., Jiang, S., Xu, G. (2018). Biomimetic fluoridated hydroxyapatite coating with micron/nano-topography on magnesium alloy for orthopaedic application. Chemical Engineering Journal, 339: 7-13. doi: 10.1016/j.cej.2018.01.083

[7] Sadat-Shojai, M., Khorasani, M.-T., Dinpanah-Khoshdargi, E., Jamshidi, A. (2013). Synthesis methods for nanosized hydroxyapatite with diverse structures. Acta biomaterialia, 9(8): 7591-7621. doi: 10.1016/j.actbio.2013.04.012

[8] Sun, R., Liu, P., Zhang, R., Lv, Y., Chen, K. (2016). Hydrothermal synthesis of microstructured fluoridated hydroxyapatite coating on magnesium alloy. Surface Engineering, 32 (11): 879-884. doi: 10.1080/02670844.2016.1194511

[9] Yu, N., Cai, S., Wang, F., Zhang, F., Ling, R., Li, Y., Jiang, Y., Xu, G. (2017). Microwave assisted deposition of strontium doped hydroxyapatite coating on AZ31 magnesium alloy with enhanced mineralization ability and corrosion resistance. Ceramics International, 43(2): 2495-2503. doi: 10.1016/j.ceramint.2016.11.050

[10] Geng, Z., Cui, Z., Li, Z., Zhu, S., Liang, Y., Liu, Y., Li, X., He, X., Yu, X., Wang, R. (2016). Strontium incorporation to optimize the antibacterial and biological characteristics of silver-substituted hydroxyapatite coating. Materials Science and Engineering: C, 58: 467-477. doi: 10.1016/j.msec.2015.08.061

[11] Zhang, M., Cai, S., Shen, S., Xu, G., Li, Y., Ling, R., Wu, X. (2016). In-situ defect repairing in hydroxyapatite/phytic acid hybrid coatings on AZ31 magnesium alloy by hydrothermal treatment. Journal of Alloys and Compounds, 658: 649-656. doi: 10.1016/j.jallcom.2015.10.282

[12] Yang, H., Xia, K., Wang, T., Niu, J., Song, Y., Xiong, Z., Zheng, K., Wei, S., Lu, W. (2016). Growth, in vitro biodegradation and cytocompatibility properties of nano-hydroxyapatite coatings on biodegradable magnesium alloys. Journal of Alloys and Compounds, 672: 366-373. doi: 10.1016/j.jallcom.2016.02.156

[13] Kang, Z., Zhang, J., Niu, L. (2018). A one-step hydrothermal process to fabricate superhydrophobic hydroxyapatite coatings and determination of their properties. Surface and Coatings Technology, 334: 84-89. doi: 10.1016/j.surfcoat.2017.11.007

[14] Li, L. Y., Cui, L. Y., Liu, B., Zeng, R. C., Chen, X. B., Li, S. Q., Wang, Z. L., Han, E. H. (2019). Corrosion resistance of glucose-induced hydrothermal calcium phosphate coating on pure magnesium. Applied Surface Science, 465: 1066-1077. doi: 10.1016/j.apsusc.2018.09.203

[15] Asl, S. K. F., Nemeth, S., Tan, M. J. (2014). Hydrothermally deposited protective and bioactive coating for magnesium alloys for implant application. Surface and Coatings Technology, 258: 931-937. doi: 10.1016/j.surfcoat.2014.07.055

[16] Wang, T., Yang, G., Zhou, W., Hu, J., Jia, W., Lu, W. (2019). One-pot hydrothermal synthesis, in vitro biodegradation and biocompatibility of Sr-doped nanorod/nanowire hydroxyapatite coatings on ZK60 magnesium alloy. Journal of Alloys and Compounds, 799: 7182. doi: 10.1016/j.jallcom.2019.05.338 
[17] Kavitha, R., Ravichandran, K., Narayanan, T. S. (2018). Deposition of strontium phosphate coatings on magnesium by hydrothermal treatment: Characteristics, corrosion resistance and bioactivity. Journal of Alloys and Compounds, 745: 725-743. doi: 10.1016/j.jallcom.2018.02.200

[18] Hiromoto, S., Tomozawa, M. (2011). Hydroxyapatite coating of AZ31 magnesium alloy by a solution treatment and its corrosion behavior in $\mathrm{NaCl}$ solution. Surface and Coatings Technology, 205(19): 4711-4719. doi: 10.1016/j.surfcoat.2011.04.036

[19] Geng, Z., Wang, R., Zhuo, X., Li, Z., Huang, Y., Ma, L., Cui, Z., Zhu, S., Liang, Y., Liu, Y. (2017). Incorporation of silver and strontium in hydroxyapatite coating on titanium surface for enhanced antibacterial and biological properties. Materials Science and Engineering: C, 71: 852-861. doi: 10.1016/j.msec.2016.10.079

[20] Lam, W., Pan, H., Li, Z., Yang, C., Chan, W., Wong, C., Luk, K., Lu, W. (2010). Strontium-substituted calcium phosphates prepared by hydrothermal method under linoleic acid-ethanol solution. Ceramics international, 36(2): 683-688. doi: 10.1016/j.ceramint.2009.10.012

[21] Tomozawa, M., Hiromoto, S. (2011). Microstructure of hydroxyapatite-and octacalcium phosphate-coatings formed on magnesium by a hydrothermal treatment at various $\mathrm{pH}$ values. Acta Materialia, 59(1): 355-363. doi: 10.1016/j.actamat.2010.09.041 